\title{
Modification of Hydrophobic Polypeptide-based Film by Blending with Hydrophilic Poly(acrylic acid)
}

\author{
Guoquan Zhu, Fagang Wang, Qiaochun Gao, Yuying Liu \\ School of Materials Science and Engineering, Shandong University of Technology, China
}

\begin{abstract}
In this study, a series of poly( $\gamma$-benzyl L-glutamate)/poly(acrylic acid) (PBLG/PAA) polymer blend films were prepared by casting the polymer blend solution in dimethylsulfoxide (DMSO). The structure and morphology of the polymer blend film were investigated by Fourier Transform Infrared Spectroscopy (FT-IR) and Scanning Electron Microscopy (SEM). Thermal, mechanical, and chemical properties of PBLG/PAA polymer blend films were studied by Differential Scanning Calorimetry (DSC), Thermogravimetric (TG) Analysis, Tensile Tests, and measurements of Surface Contact Angles. The results revealed that the introduction of PAA could exert great effects on the structure and properties of the polypeptide films.
\end{abstract}

Keywords: Modification, PBLG/PAA, film, blend.

\section{Introduction}

In recent years, polypeptides and their copolymers have received much attention for their potential applications ${ }^{[1-8]}$. Based on their unique structures and properties, polypeptides and their copolymers have been investigated widely in the fields of functional biomaterials, protein simulation, polymer carriers for protein conjugates, macromolecular conformational study, catalysis, nanoreactors, drug delivery systems etc ${ }^{[9-13]}$. Also, for polypeptide films, an important application is for temporary artificial skin substrates in burn therapy ${ }^{[1,3]}$.

Nowadays, polymer blending has been a highly useful method for the improvement or modification of the physicochemical properties of polymer materials ${ }^{[14]}$. An important property of the polymer blend is the miscibility of its ingredients, as it affects the mechanical properties, morphology, permeability, and degradation ${ }^{[14,15]}$. Lots of researches regarding the miscibility in multi-component polymer systems have been reported. Among them, the polymer blends between biopolymers and synthetic polymers are of particular significance as they could be used as biomedical and biodegradable materials ${ }^{[16-18]}$.

Compared with pure polypeptide, polypeptide/biopolymer blends have received relatively little attention. As known, PBLG is hydrophobic and the hydrophobicity limits its application, while PAA holds good hydrophilicity and biocompatibility ${ }^{[19-21]}$, the introduction of PAA into PBLG is expected to change the properties of the polypeptide. Up to date, to the best of our knowledge, no experimental work has so far been reported on the properties of PBLG/PAA blend film. In this study, PBLG/PAA polymer blend films were prepared by casting the polymer blend solution in DMSO. Structure and morphology of the polymer blend film were investigated by FT-IR and SEM. Thermal, mechanical, and chemical properties of the polymer blend films were studied by DSC, TG Analysis, Tensile Tests, and Surface Contact Angle Tests. It was revealed that the introduction of PAA could exert marked effects on the structure and the properties of the polypeptide films.

\section{Experimental}

\section{Materials}

Poly(acrylic acid) $\left(M_{\mathrm{w}}=100000\right)$ was purchased from Aldrich Chemical Co. (USA), and used without further purification. Hexane, tetrahydrofuran (THF) and 1,4-dioxane are of analytical grade and dried with sodium to remove water before use. Dimethylsulfoxide (DMSO) and other solvents are of analytical grade and used without further purification.

\section{Synthesis of polypeptide homopolymer}

The PBLG homopolymer was synthesized by a standard $N$-carboxyl- $\gamma$-benzyl- $L$-glutamate anhydride (NCA) method ${ }^{[4]}$. The molecular weight of PBLG was estimated from the intrinsic viscosity measured in dichloroacetic acid (DCA) ${ }^{[22]}$. The molecular weight of PBLG used in the study was about 150000 .

\section{Preparation of PBLG/PAA polymer blend film}

Polymer blend films were prepared by casting films from a $30 \%$ polymer blend solution in DMSO onto clean glass plates and drying them under vacuum at $60{ }^{\circ} \mathrm{C}$. Also, it is found that, when PAA mole content in polymer blend is over $15 \%$, the polymer blend can not form continuous film. Figure 1 presents the proposed structure of PBLG/PAA blend film showing the H-bonding interaction between PBLG and PAA.

\section{FT-IR measurements}

FT-IR spectra of PBLG, PAA, and PBLG/PAA blend were measured on a Nicolet 5700 FT-IR spectrometer between 4000 and $400 \mathrm{~cm}^{-1}$.

\section{SEM observations}

SEM investigation was carried out using a scanning electron microscope (Sirin 200, FEI, Holland). Gold was sprayed on polymer blend films in vacuum. Acceleration voltage was $10 \mathrm{kV}$. 


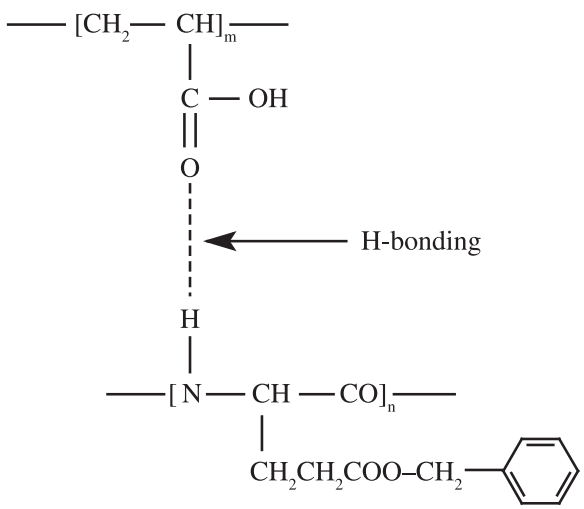

Figure 1. Proposed structure of PBLG/PAA blend film showing the $\mathrm{H}$-bonding interaction between PBLG and PAA.

\section{DSC measurements}

DSC measurements were made on a DSC Q100 (USA) differential scanning calorimeter, the temperature calibrated with indium in nitrogen atmosphere. About $7 \mathrm{mg}$ sample was weighted very accurately. The temperature was controlled within the range between $0{ }^{\circ} \mathrm{C}$ and $450{ }^{\circ} \mathrm{C}$, the heating rate was $10^{\circ} \mathrm{C} / \mathrm{min}$.

\section{Thermogravimetric (TG) analysis}

Thermogravimetric (TG) analysis was carried out on a NETZSCH STA 4490 C TG-DTA analyzer (Germany) at a heating rate of $10{ }^{\circ} \mathrm{C} / \mathrm{min}$ under nitrogen atmosphere over the temperature range of $20-650^{\circ} \mathrm{C}$. Samples of approximately $13 \mathrm{mg}$ were used for the TGA measurements.

\section{Tensile tests}

Tensile tests were carried out with an Instron Model 4468 universal testing machine (Digital Instruments, USA) according to the standard ISO1184-1983. The crosshead speed was set to $60 \mathrm{~mm} / \mathrm{min}$. For each data point, five samples were tested and the average value was taken.

\section{Surface contact angle tests}

The static contact angle was measured with an optical contact angle meter CAM 200 (KSV Instrument Ltd., Finland). A $5 \mu \mathrm{L}$ drop of pure distilled water was placed on the polymer blend film surface using a syringe with a 22-gauge needle. The measurements of each contact angle were performed within $10 \mathrm{~s}$ after each drop to ensure that the droplet did not soak into the compact. The surface contact angles were the mean of five determinations ${ }^{[23]}$.

\section{Results and Discussion}

\section{FT-IR analysis}

Curves $a, b$, and $c$ in Figure 2 present the FT-IR spectra of PBLG, PAA, and PBLG/PAA blend, respectively. In PBLG spectrum, the typical peak appearing at $1733 \mathrm{~cm}^{-1}$ (corresponding to $\mathrm{C}=\mathrm{O}$ stretching band of the ester group in the side chain), the typical peak appearing at $3287 \mathrm{~cm}^{-1}$ (corresponding to $\mathrm{N}-\mathrm{H}$ stretching vibration), the typical peaks appearing at $1655 \mathrm{~cm}^{-1}$ and $1550 \mathrm{~cm}^{-1}$ (corresponding to the $\alpha$-helix amide I band and the $\alpha$-helix amide II band, respectively) are detected $^{[7]}$. In PAA spectrum, the typical peak appearing at $3553 \mathrm{~cm}^{-1}$ (corresponding to hydroxyl groups), the typical peak appearing at $1718 \mathrm{~cm}^{-1}$ (corresponding to carbonyl groups) are detected ${ }^{[19]}$. In

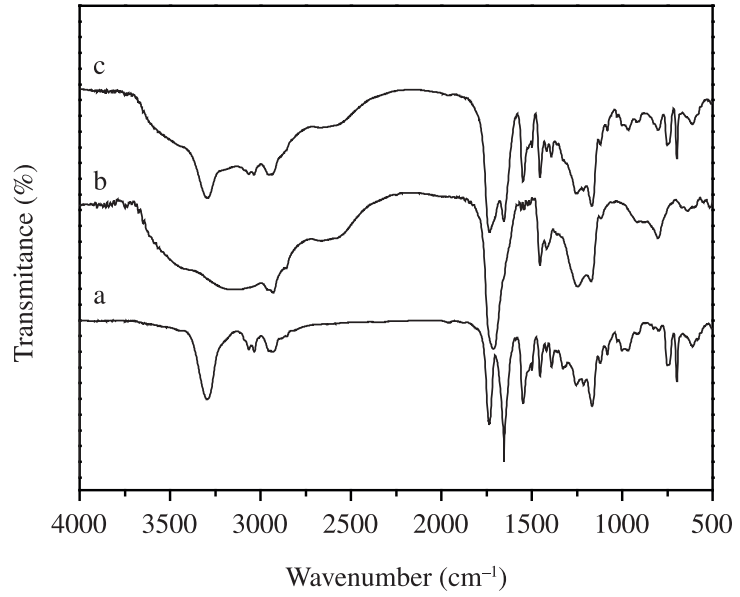

Figure 2. FT-IR spectra of (a) PBLG, (b) PAA, and (c) PBLG/PAA blend (PAA mole content: $14 \%$ ).

PBLG/PAA blend spectrum, the typical peaks of both PBLG segments and PAA segments are all detected and no new typical peaks appear, indicating that PBLG and PAA hold miscibility and no new chemical bonds formed when PBLG blends with PAA.

\section{SEM analysis}

The surface morphologies of PBLG/PAA bend films were studied by SEM technique. Figure 3 shows the SEM photographs of PBLG/PAA blend film surface with different PAA mole contents: (a) 0, (b) 7\%, and (c) 14\% (magnification 2000x). As seen from Figure 3, the introduction of PAA changed the surface morphologies of the polymer blend films. With the increase of PAA mole contents, the surface morphologies of polymer blend films became coarse and discontinuous, and the phase-separation phenomenon appears. As shown in Figure 1, PAA chains and PBLG segments could interact by forming intermolecular hydrogen bonds. This phenomenon suggests that the change of the surface morphologies of the polymer blend films could be attributed to the introduction of PAA chains.

\section{DSC analysis}

Figure 4 indicates the DSC curves of PBLG/PAA blend films with two PAA mole contents: (a) 0 and (b) $14 \%$. By comparing curves $a$ and $b$, it is found that the melting temperature of PBLG segments in polymer blend decreases with the increase of the PAA mole contents. As mentioned above, the PAA chains and the PBLG segments could interact by forming intermolecular hydrogen bonds and the interaction partially destroyed the intermolecular or intramolecular hydrogen bonds of PBLG segments ${ }^{[24]}$. This situation indicates that the decrease of the melting temperature of PBLG segments in polymer blend was related to the introduction of PAA segments.

\section{Thermogravimetric (TG) analysis}

Figures 5 and 6 present the TG and the DTG curves of PBLG/PAA blend films with two PAA mole contents: (a) 0 and (b) $14 \%$, respectively, the corresponding data are listed in Table 1. As it can be seen from Figure 5 and Table 1, the initial decomposition temperature of PBLG segments in polymer blend decreases with the increase of PAA mole contents. Also seen from Figure 6 and Table 1, the maximum decomposition temperature of PBLG segments in the polymer blend also decreases with the increase of the PAA mole contents. As discussed above, the interaction between PBLG segments and PAA chains could partially destroy the intermolecular 
or intramolecular hydrogen bonds of PBLG segments ${ }^{[24]}$, suggesting that the decrease of both the initial decompositon temperature and the maximum decomposition temperature of PBLG segments in polymer blend were connected with the introduction of PAA chains.

\section{Tensile tests}

Figure 7 shows the relationship between the tensile strength of PBLG/PAA blend films and PAA mole contents. As is shown in

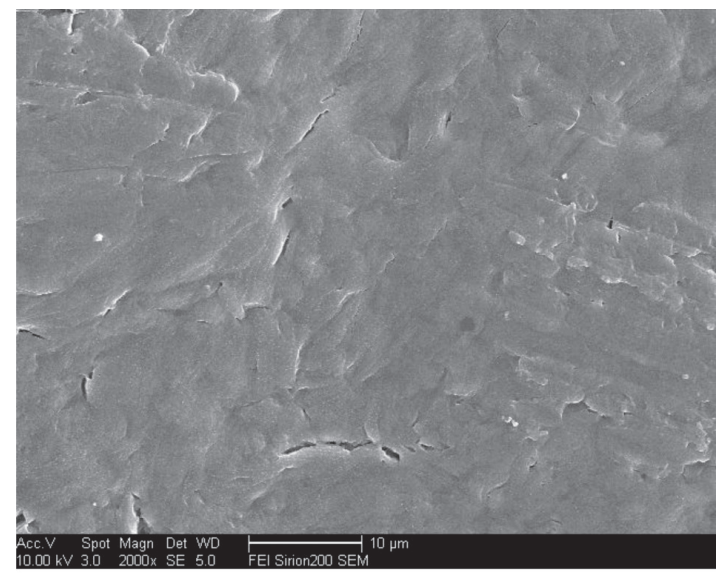

(a)

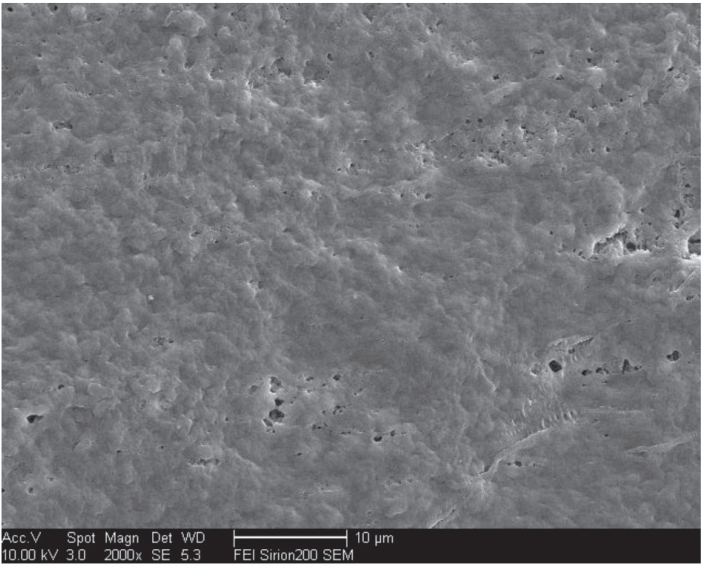

(b)

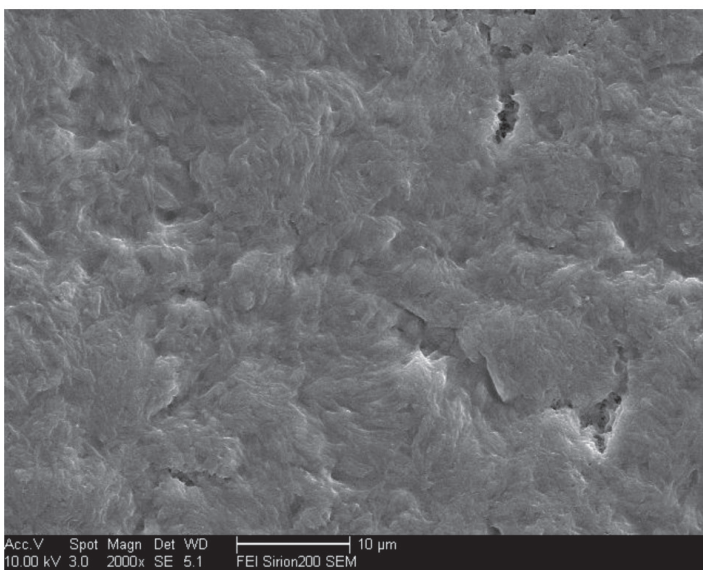

(c)

Figure 3. SEM photographs of PBLG/PAA blend film surface with different PAA mole contents: (a) 0, (b) 7\%, and (c) 14\% (magnification 2000x).
Figure 7, the tensile strength of the polymer blend film decreases with the increase of PAA mole contents. As mentioned above, the interaction between the PAA segments and the polypeptide chains could destroy the intermolecular or intramolecular hydrogen bonds of the polypeptide segments, indicating the decrease of the tensile strength of polymer blend film was related with the introduction of PAA chains.

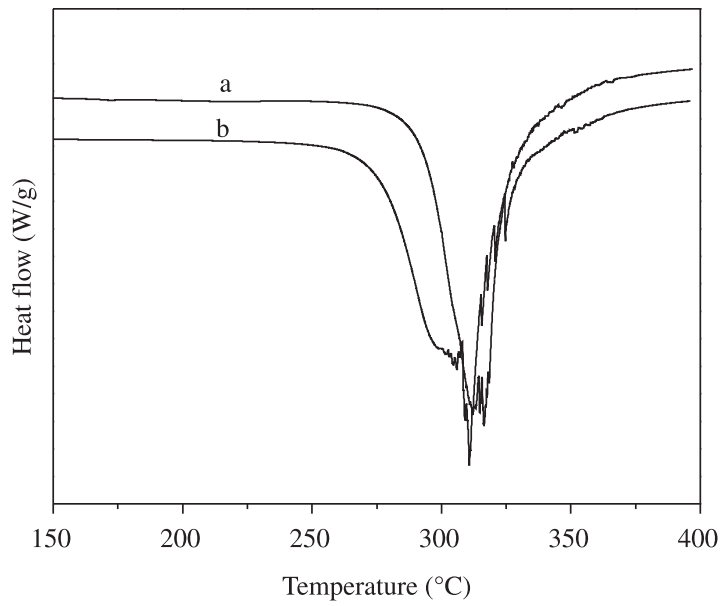

Figure 4. DSC curves of PBLG/PAA blend films with two PAA mole contents: (a) 0 and (b) $14 \%$.

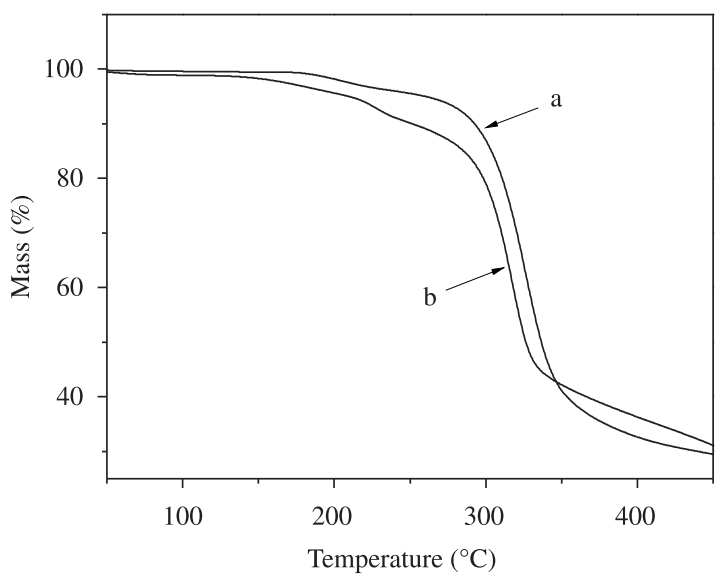

Figure 5. TG curves of PBLG/PAA blend films with two PAA mole contents: (a) 0 and (b) $14 \%$.

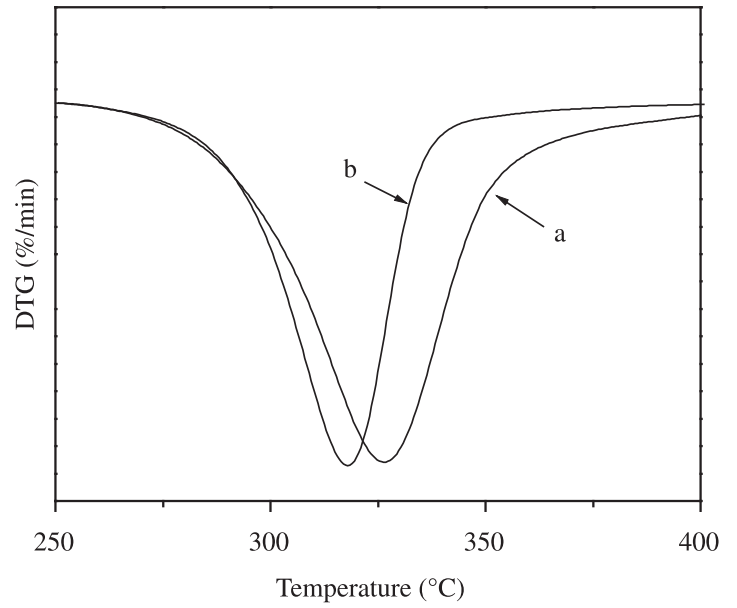

Figure 6. DTG curves of PBLG/PAA blend films with two PAA mole contents: (a) 0 and (b) $14 \%$. 
Table 1. Thermal decomposition temperature of PBLG segments in polymer blend with different PAA mole content.

\begin{tabular}{ccc}
\hline $\begin{array}{c}\text { PAA content }(\mathbf{m o l} \\
\%)\end{array}$ & $\left.T_{\text {ini }}{ }^{\mathrm{a}}{ }^{\circ} \mathbf{C}\right)$ & $T_{\max }{ }^{\mathrm{b}}\left({ }^{\circ} \mathbf{C}\right)$ \\
\hline 0 & 248.3 & 326.4 \\
14 & 245.1 & 319.6 \\
\hline
\end{tabular}

${ }^{\mathrm{a}} T_{\text {ini }}$ presents the initial decomposition temperature; ${ }^{\mathrm{b}} T_{\max }$ presents the maximum decomposition temperature.

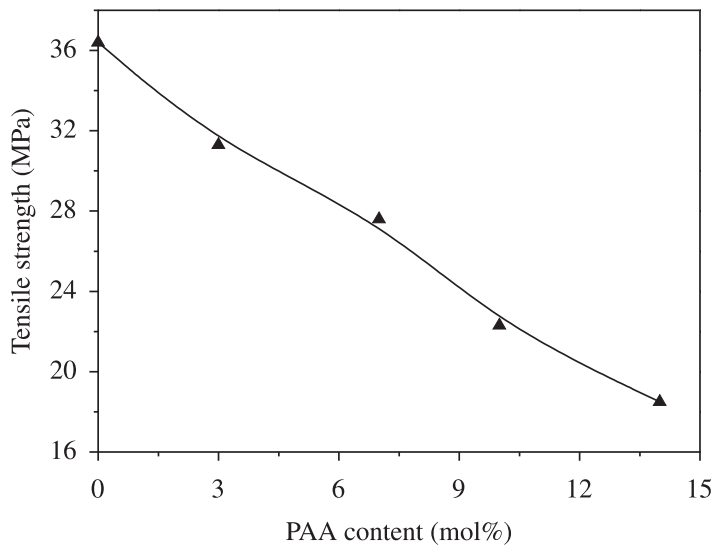

Figure 7. Relationship between the tensile strengh of PBLG/PAA blend films and PAA mole contents.

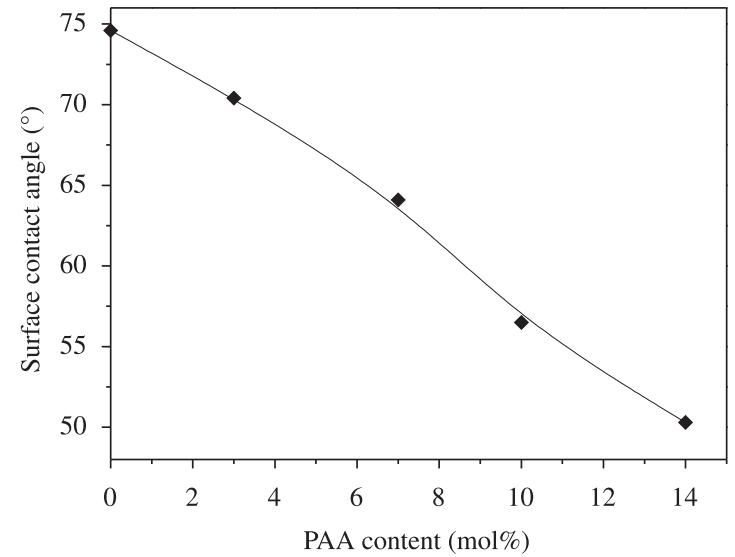

Figure 8. Relationship between the surface contact angle of PBLG/PAA blend films and PAA mole contents.

\section{Surface contact angle tests}

Figure 8 displays the relationship between the surface contact angle of PBLG/PAA blend films and PAA mole contents. As shown in Figure 8, the surface contact angle of the polymer blend film decreased with the increase of PAA mole contents, suggesting the hydrophilicity of the polymer film increased. As known, PAA segments hold good hydrophilicity, indicating the decrease of the surface contact angle of the polymer blend film was concerned with the introduction of PAA segments. Under studied or evaluated PAA contents, the higher the PAA contents, the lower the surface contact angle of the polymer blend film.

\section{Conclusion}

A series of PBLG/PAA blend films were prepared by casting the polymer blend solution in DMSO. FT-IR analysis indicated that PBLG segments and PAA chains hold miscibility. SEM photographs showed that the introduction of PAA chains changed the surface morphology of the polypeptide film. DSC data demonstrated that the melting temperature of PBLG segments in the polymer blend decreased with the increase of PAA content. TG tests indicated that both the initial decomposition temperature and the maximum decomposition temperature of PBLG segments in the polymer blend decreased with the increase of PAA content. Tensile tests verified that the tensile strength of the polymer blend film decreased with the increase of PAA content. Surface contact angle measurements proved that the introduction of PAA chains increased the hydrophilicity of the polymer blend film.

\section{Acknowledgements}

This work is supported by the Natural Science Foundation of Shandong Province (No. ZR2011EMM009).

\section{References}

1. Jokei, K.; Oka, M.; Hayashi, T. \& Miyachi, Y. - Eur. Polym. J., 35, p.945 (1999). http://dx.doi.org/10.1016/S0014-3057(98)00051-2

2. Lin, J. P.; Zhu, G. Q.; Zhu, X. M.; Lin, S. L.; Nose, T. \& Ding, W. W. - Polymer, 49, p.1132 (2008). http://dx.doi.org/10.1016/j. polymer.2008.01.021

3. Miyachi, Y.; Jokei, K.; Oka, M. \& Hayashi, T. - Eur. Polym. J., 35, p.767 (1999). http://dx.doi.org/10.1016/S0014-3057(98)00059-7

4. Tang, D. M.; Lin, J. P.; Lin, S. L.; Zhang, S. N.; Chen, T. \& Tian, X. H. - Macromol. Rapid Commun., 25, p.1241 (2004). http://dx.doi. org/10.1002/marc.200400100

5. Oh, I.; Lee, K.; Kwon, H. Y.; Lee, Y. B.; Shin, S. C.; Cho, C. S. \& Kim, C. K. - Int. J. Pharm., 181, p.107 (1999). http://dx.doi.org/10.1016/ S0378-5173(99)00012-5

6. Zhu, G. Q.; Feng, L. \& Zhang, S. N. - J. Macromol. Sci. A, 46, p.694 (2009).

7. Higashi, N.; Kawahara, J. \& Niwa, M. - J. Colloid Interf. Sci., 288, p.83 (2005). PMid:15927565. http://dx.doi.org/10.1016/j.jcis.2005.02.086

8. Zhu, G. Q. - Chem. Pap., 64, p.34 (2010). http://dx.doi.org/10.2478/ s11696-009-0090-y

9. Gao, Z.; Desjardins, A. \& Eisenberg, A. - Macromolecules, 25, p.1300 (1992). http://dx.doi.org/10.1021/ma00030a015

10. Zhong, X. F.; Varshney, S. K. \& Eisenberg, A. - Macromolecules, 25, p.7160 (1992). http://dx.doi.org/10.1021/ma00052a014

11. Zhu, G. Q. - J. Macromol. Sci. A, 46, p.892 (2009).

12. Lin, J. P.; Zhang, S. N.; Chen, T.; Lin, S. L. \& Jin, H. - Int. J. Pharm., 336, p.49 (2007). PMid:17134858. http://dx.doi.org/10.1016/j. ijpharm.2006.11.026

13. Moffitt, M. \& Eisenberg, A. - Macromolecules, 30, p.4363 (1997). http://dx.doi.org/10.1021/ma961577x

14. Park, J. S.; Park, J. W. \& Ruckenstein, E. - Polymer, 42, p.4271 (2001). http://dx.doi.org/10.1016/S0032-3861(00)00768-0

15. Nishio, Y. \& Manley, R. - Macromolecules, 21, p.1270 (1988). http:// dx.doi.org/10.1021/ma00183a016

16. Kondo, T.; Sawatari, C.; Manley, R. \& Gray, D. G. - Macromolecules, 27, p.210 (1994). http://dx.doi.org/10.1021/ma00079a031

17. Sawatari, C. \& Kondo, T. - Macromolecules, 32, p.1949 (1999). http:// dx.doi.org/10.1021/ma980900o

18. Lio, K.; Minoura, N. \& Nagura, M. - Polymer, 36, p.2579 (1995). http://dx.doi.org/10.1016/0032-3861(95)91204-K

19. Kaczmarek, H. \& Szalla, A. - J. Photochem. Photobio. A, 180, p.46 (2006). http://dx.doi.org/10.1016/j.jphotochem.2005.09.014

20. Lee, K. R.; Teng, M. Y.; Lee, H. H. \& Lai, J. Y. - J. Membrane Sci., 164, p.13 (2000). http://dx.doi.org/10.1016/S0376-7388(99)00097-6 
21. Wu, G. M.; Lin, S. J. \& Yang, C. C. - J. Membrane Sci., 275, p.127 (2006). http://dx.doi.org/10.1016/j.memsci.2005.09.012

22. Abe, A. \& Yamazaki, T. - Macromolecules, 22, p.2138 (1989). http:// dx.doi.org/10.1021/ma00195a023

23. Bai, L. Q.; Zhu, L. J.; Min, S. J.; Liu, L.; Cai, Y. R. \& Yao, J. M. - Appl. Surf. Sci., 254, p.2988 (2008). http://dx.doi.org/10.1016/j. apsusc.2007.10.049
24. Cho, C. S.; Jeong, Y. I.; Kim, S. H.; Nah, J. W.; Kubota, M. \& Komoto, T. - Polymer, 41, p.5185 (2000). http://dx.doi.org/10.1016/S00323861(99)00746-6

Enviado: $25 / 02 / 12$

Reenviado: $27 / 04 / 12$

Aceito: $23 / 07 / 12$ 